\title{
Expansins: roles in plant growth and potential applications in crop improvement
}

\author{
Prince Marowa $^{1}$ Anming Ding ${ }^{1} \cdot$ Yingzhen Kong $^{1}$
}

Received: 10 December 2015/Accepted: 2 February 2016/Published online: 18 February 2016

(c) The Author(s) 2016. This article is published with open access at Springerlink.com

\begin{abstract}
Key message Results from various expansin related studies have demonstrated that expansins present an opportunity to improve various crops in many different aspects ranging from yield and fruit ripening to improved stress tolerance.

Abstract The recent advances in expansin studies were reviewed. Besides producing the strength that is needed by the plants, cell walls define cell shape, cell size and cell function. Expansins are cell wall proteins which consist of four sub families; $\alpha$-expansin, $\beta$-expansin, expansin-like A and expansin-like $B$. These proteins mediate cell wall loosening and they are present in all plants and in some microbial organisms and other organisms like snails. Decades after their initial discovery in cucumber, it is now clear that these small proteins have diverse biological roles in plants. Through their ability to enable the local sliding of wall polymers by reducing adhesion between adjacent wall polysaccharides and the part they play in cell wall remodeling after cytokinesis, it is now clear that expansins are required in almost all plant physiological development aspects from germination to fruiting. This is shown by the various reports from different studies using various molecular biology approaches such as gene achieve these many roles through their non-enzymatic wall loosening ability. This paper reviews and summarizes some of the
\end{abstract}

Communicated by N. Stewart.

Yingzhen Kong

kongyingzhen@163.com; kongyingzhen@caas.cn

1 Key Laboratory for Tobacco Gene Resources, Tobacco Research Institute, Chinese Academy of Agricultural Sciences, Qingdao 266101, People's Republic of China reported functions of expansins and outlines the potential uses of expansins in crop improvement programs.

Keywords Cell wall $\cdot$ Expansin $\cdot$ Plant growth $\cdot$ Cell wall loosening · Crop improvement $\cdot$ Abiotic stress $\cdot$ Biotic stress

\section{Introduction}

When the expansins were first discovered in cucumber hypocotyls (McQueen-Mason et al. 1992), they were reported to loosen plant cell walls in a non-enzymatic but $\mathrm{pH}$ dependent manner. The plant cell wall which consists of a primary and secondary cell wall is an important plant feature. Cells of higher plants have a protective cell wall which is basically made up of polysaccharides such as cellulose, hemicellulose and some pectins which are crosslinked together and embedded in an amorphous gel-like matrix. The molecular lengths of some hemicellulosic polysaccharides like xyloglucans are longer than the distance between cellulose microfibrils. This enables them to cross-link adjacent cellulose microfibrils to tether together and coat the surface of the cellulose microfibrils thus forming the cellulose/hemicellulose network that functions as the major tension-bearing framework of the primary cell wall and conferring extensibility to the network structure (Fukuda 2014). The dynamics of the cell wall determines cell shape, functions during development, responde to environmental cues and contributing to the strength and structural integrity of the cell and the whole plant at large.

There is constant assembly, remodeling and disassembly of the cell wall during the plant's lifetime. This is achieved through the action of the many various types of structural and functional components such as expansins which are 
secreted into the cell wall space (Fukuda 2014). This constant assembly, remodeling and disassembly of the cell wall is necessary for plant growth and acclimatization. Fukuda (2014) defined cell wall loosening as a continuous reduction in cell wall tensile strength and highlighted that this cell wall loosening is a direct cause of cell wall expansion which subsequently results in cell expansion. This process is crucial because it is the basis of plant growth. The rearrangement of the cellulose/xyloglucan networks which is thought to be achieved through either the remodeling action of expansin genes or molecular grafting between xyloglucan cross-links by means of endotransglucosylation reaction (Fukuda 2014) is vital for plant growth and development.

The cell wall plays crucial roles in various cell activities such as differentiation, transport and communication, senescence, abscission, plant-pathogen interactions and ultimately plant growth. It provides both the mechanical strength needed by the plant and the plasticity that is necessary for the development of plant tissues and organs. Since plant growth can be generalized as a function of cell size and cell number, plant growth and development therefore requires modulation of cell size and shape, which is accomplished by regulated changes in cell wall plasticity. This makes expansins very important since they are actively involved in this area (Cosgrove 2000, 2015; Fukuda 2014; McQueen-Mason et al. 1992; Sampedro and Cosgrove 2005; Zou et al. 2015). Although the expansin's biochemical working mechanism is not completely understood, it is generally agreed that the action of expansin on the cell wall brings about this much needed plasticity (Cosgrove 2000). Biomechanical analysis by creep tests showed that AtEXLA2 overexpression has the ability to decrease the wall strength in Arabidopsis thaliana (Arabidopsis) hypocotyls (Boron et al. 2015).

Expansins comprise a large gene super-family which codes for small (225-300 amino acid residues) cell wall proteins (Fukuda 2014; Sampedro and Cosgrove 2005). According to Kende et al. (2004) they can be divided into four sub families; $\alpha$-expansin or expansin A (hereinafter referred to as "EXPA"), $\beta$-expansin or expansin B (hereinafter referred to as "EXPB"), expansin-like A (hereinafter referred to as "EXPLA") and expansin-like B (hereinafter referred to as "EXPLB"). Choi et al. (2008) concurred with this classification but went on to add expansin-like X (hereinafter referred to as "EXLX") as another group of expansins which are remotely related to expansin genes and found both inside and outside the plant kingdom. The classification of expansin and expansin-like genes is based on their phylogenetic relationship and this has been extensively reviewed (Kende et al. 2004; Lee et al. 2001; Li et al. 2003b).
Expansins have the ability to non-enzymatically trigger a $\mathrm{pH}$ dependent relaxation of the cell wall which loosens and softens it thus enabling cell expansion. It has been noted that due to the action of expansins, growing plant cell walls extend faster at low $\mathrm{pH}$ (4.5), a phenomenon which Rayle and Cleland (1992) preferred to call acid growth. This $\mathrm{pH}$ change is brought about by the action of the $\mathrm{H}^{+}$ATPase in the plasma membrane which pumps protons into the cell wall (Cosgrove 2000). However, besides $\mathrm{pH}$, the action of expansins can also be influenced by several other factors including environmental factors (Brummell et al. 1999) such as flooding (Vreeburg et al. 2005) or submergence (Lee and Kende 2001) and hormones like abscisic acid, indole-3-acetic acid (Zhao et al. 2012), auxins (McQueen-Mason et al. 1992), brassinosteroids (Park et al. 2010), cytokinins (Downes and Crowell 1998) and ethylene (Belfield et al. 2005). In this review we will not dwell much on the history, classification and structure of expansins since these and other related matters have been extensively dealt with in earlier reviews (Choi et al. 2008; Cosgrove 2015; Cosgrove et al. 2002; Lee et al. 2001; Sampedro and Cosgrove 2005). This paper will focus mainly on the recent progress and findings from expansin related research and highlights possible uses of expansins in crop improvement programs since an earlier review by Choi et al. (2008) covered a lot of ground with respect to nomenclature of expansin genes, their evolution, biochemical and biophysical properties and their relationship with plant growth and development.

As stated earlier on, plant growth results from an increase in cell size and cell number, thus making cell expansion an important aspect of plant growth and development. This cell expansion however must overcome resistance from the protective cell wall. Among other possible means, cell expansion is achieved through the action of expansin genes on the cell wall where they are thought to act like a zipper and break the hydrogen bonds linking cell wall polysaccharides (Bashline et al. 2014). Although the details of expansin action have not yet been fully elucidated (Dal Santo et al. 2013) they are reported to target hydrogen bonds linking cellulose and hemicellulose especially xyloglucan thus loosening the cell wall. This enables the cell wall polymers to slide and consequently allowing the cell to expand (Bashline et al. 2014; Fukuda 2014).

Results from many experiments have shown that expansins are very important to plants. It has been demonstrated that expansins affect almost all plant growth phases and have the potential to influence plant-biotic/ abiotic stress relationship (Table 1). Phylogenetic analysis of some of the studied expansin genes shows that different expansins from various species falling within the same 
Table 1 Selected examples of studies reporting the effects of expansins on plant development and stress adaptation

\begin{tabular}{|c|c|c|c|c|}
\hline $\begin{array}{l}\text { Expansin } \\
\text { name }\end{array}$ & Sub-family & Mode of expression & Observed phenotype & References \\
\hline AtEXPA1 & $\alpha$-Expansin & $\begin{array}{l}\text { Overexpression and } \\
\text { inhibition }\end{array}$ & $\begin{array}{l}\text { Increased rate of light-induced stomatal opening and } \\
\text { reduced sensitivity of stomata to the stimuli, respectively }\end{array}$ & Wei et al. $(2011 \mathrm{a}, \mathrm{b})$ \\
\hline AtEXPA2 & $\alpha$-Expansin & $\begin{array}{l}\text { Overexpression and } \\
\text { suppression }\end{array}$ & $\begin{array}{l}\text { Overexpressors germinated faster than wild type plants } \\
\text { while germination was delayed in mutant lines }\end{array}$ & Yan et al. (2014) \\
\hline$A t E X P 3$ & $\alpha$-Expansin & Overexpression & $\begin{array}{l}\text { Enhanced growth and larger leaves under normal growth } \\
\text { conditions }\end{array}$ & Kwon et al. (2008) \\
\hline AtEXPA4 & $\alpha$-Expansin & $\begin{array}{l}\text { Expression profile } \\
\text { analyses }\end{array}$ & Thought to soften the cell wall of the stigma & Mollet et al. (2013) \\
\hline AtEXPA7 & $\alpha$-Expansin & Overexpression & Influenced root hair initiation and root growth & Cho and Cosgrove (2002) \\
\hline AtEXPA10 & $\alpha$-Expansin & Overexpression & Large plant cells, larger leaves and longer stems & Kuluev et al. (2012) \\
\hline AtEXPA17 & $\alpha$-Expansin & $\begin{array}{l}\text { Overexpression and } \\
\text { knock down }\end{array}$ & Enhanced and reduced lateral root formation, respectively & Lee and Kim (2013) \\
\hline AtEXPA18 & $\alpha$-Expansin & Overexpression & Influenced root hair initiation and root growth & Cho and Cosgrove (2002) \\
\hline LeEXPA1 & $\alpha$-Expansin & Expression analysis & Proposed to be involved in fruit softening & Rose et al. $(1997,2000)$ \\
\hline LeEXP1 & $\alpha$-Expansin & $\begin{array}{l}\text { Overexpression and } \\
\text { Suppression }\end{array}$ & $\begin{array}{l}\text { Overexpression of the gene resulted in softer fruits while its } \\
\text { suppression produced firmer fruits in transgenic tomatoes }\end{array}$ & Brummell et al. (1999) \\
\hline LeEXPA8 & $\alpha$-Expansin & $\begin{array}{l}\text { mRNA expression } \\
\text { analysis }\end{array}$ & $\begin{array}{l}\text { Thought to influence germination since it is expressed in } \\
\text { germinating seeds only and appears to be involved during } \\
\text { the initial elongation of the radicle }\end{array}$ & Chen et al. (2001) \\
\hline LeEXPA10 & $\alpha$-Expansin & $\begin{array}{l}\text { mRNA expression } \\
\text { analysis }\end{array}$ & $\begin{array}{l}\text { Thought to influence germination as well as seed } \\
\text { development }\end{array}$ & Chen et al. (2001) \\
\hline SlExp1 & & Knockout & Increased fruit firmness & Minoia et al. (2015) \\
\hline OsEXPA1 & $\alpha$-Expansin & Expression analysis & Thought to influence coleoptile and internode development & Cho and Kende (1997b) \\
\hline OsEXPA4 & $\alpha$-Expansin & $\begin{array}{l}\text { Overexpression } \\
\text { Antisense (RNAi) }\end{array}$ & $\begin{array}{l}\text { Pleiotropic phenotypes in plant height, leaf number, } \\
\text { flowering time and seed set as well as enhanced coleoptile } \\
\text { growth } \\
\text { Shorter plants, decreased coleoptile and mesocotyl lengths }\end{array}$ & $\begin{array}{l}\text { Choi et al. (2003) } \\
\text { Zou et al. (2015) }\end{array}$ \\
\hline OsEXPA8 & $\alpha$-Expansin & Overexpression & $\begin{array}{l}\text { Increased root mass, number and size of leaves as well as } \\
\text { plant height }\end{array}$ & Ma et al. (2013) \\
\hline OsEXPA17 & $\alpha$-Expansin & Overexpression & Influenced rice root development & Yu et al. (2011) \\
\hline$D z E X P 1$ & $\alpha$-Expansin & Expression analysis & $\begin{array}{l}\text { Thought to be involved in fruit/pulp softening and peel } \\
\text { dehiscence }\end{array}$ & Palapol et al. (2015) \\
\hline NtEXPA5 & $\alpha$-Expansin & Overexpression & Increased organ size especially the leaves and the stem & Kuluev et al. (2013) \\
\hline$D z E X P 2$ & $\alpha$-Expansin & Expression analysis & $\begin{array}{l}\text { Thought to be involved in fruit/pulp softening as well as } \\
\text { peel dehiscence }\end{array}$ & Palapol et al. 2015) \\
\hline FaExp2 & $\alpha$-Expansin & Expression analysis & $\begin{array}{l}\text { Thought to take part in cell wall polymer disassembly } \\
\text { during fruit ripening }\end{array}$ & Civello et al. (1999) \\
\hline MaExpl & & Overexpression & Thought to affect banana ripening & Asif et al. (2014) \\
\hline PpEXP1 & $\alpha$-Expansin & Overexpression & Enhanced germination and abiotic stresses tolerance & Xu et al. (2014) \\
\hline$R h E X P A 4$ & $\alpha$-Expansin & $\begin{array}{l}\text { Overexpression } \\
\text { Overexpression and } \\
\text { silencing }\end{array}$ & $\begin{array}{l}\text { Higher germination percentage; increased lateral root } \\
\text { formation and modified leaves } \\
\text { Affected expansion and dehydration tolerance of rose petals }\end{array}$ & $\begin{array}{l}\text { Lü et al. (2013) } \\
\text { Dai et al. (2012) }\end{array}$ \\
\hline$G m E X P 1$ & $\alpha$-Expansin & Overexpression & Accelerated root growth & Lee et al. (2003) \\
\hline GbEXPATR & $\alpha$-Expansin & Overexpression & Enhanced root hair development in transgenic Arabidopsis & Li et al. (2015b) \\
\hline$I b E X P 1$ & & Overexpression & More rosette leaves & Bae et al. (2014) \\
\hline PnEXPA1 & $\alpha$-Expansin & Overexpression & Large plant cells, larger leaves and longer stems & Kuluev et al. (2012) \\
\hline CsEXPA1 & $\alpha$-Expansin & Overexpression & Initiated development of the leaf primordium & Pien et al. (2001) \\
\hline AtEXPB1 & $\beta$-Expansin & Overexpression & $\begin{array}{l}\text { significantly longer petioles under normal growth } \\
\text { conditions }\end{array}$ & Kwon et al. (2008) \\
\hline AtEXPB5 & $\beta$-Expansin & $\begin{array}{l}\text { Expression profile } \\
\text { analyses }\end{array}$ & Thought to soften the cell wall of the stigma & Mollet et al. (2013) \\
\hline
\end{tabular}


Table 1 continued

\begin{tabular}{|c|c|c|c|c|}
\hline $\begin{array}{l}\text { Expansin } \\
\text { name }\end{array}$ & Sub-family & Mode of expression & Observed phenotype & References \\
\hline OsEXPB2 & $\beta$-Expansin & $\begin{array}{l}\text { Expression analysis } \\
\text { Silenced }\end{array}$ & $\begin{array}{l}\text { Thought to influence root hair and internodes development } \\
\text { Confirmed the earlier suggested role as shown by } \\
\text { physiological changes including reduced root and leaf } \\
\text { sizes }\end{array}$ & $\begin{array}{l}\text { Cho and Kende (1997b) } \\
\text { Zou et al. (2015) }\end{array}$ \\
\hline OsEXPB3 & $\beta$-Expansin & Expression analysis & $\begin{array}{l}\text { Thought to be involved in internode elongation as well as } \\
\text { root development }\end{array}$ & $\begin{array}{l}\text { Cho and Kende (1997b; Lee } \\
\text { and Kende (2001) }\end{array}$ \\
\hline OsEXPB4 & $\beta$-Expansin & Expression analysis & $\begin{array}{l}\text { mRNA accumulation correlated well with internode } \\
\text { elongation }\end{array}$ & Lee and Kende (2001) \\
\hline OsEXPB6 & $\beta$-Expansin & Expression analysis & $\begin{array}{l}\text { mRNA accumulation correlated well with internode } \\
\text { elongation }\end{array}$ & Lee and Kende (2001) \\
\hline OsEXPB11 & $\beta$-Expansin & Expression analysis & $\begin{array}{l}\text { mRNA accumulation correlated well with internode } \\
\text { elongation }\end{array}$ & Lee and Kende (2001) \\
\hline GmEXPB2 & $\beta$-Expansin & Overexpression & $\begin{array}{l}\text { Enhanced overall plant growth, higher root cell division } \\
\text { and elongation. Enhanced phosphorus uptake }\end{array}$ & Guo et al. (2011) \\
\hline GmEXPB2 & $\beta$-Expansin & Overexpression & Increase in phosphorus efficiency & Zhou et al. (2014) \\
\hline ТаEXРВ23 & $\beta$-Expansin & Overexpression & $\begin{array}{l}\text { Improved tolerance of transgenic tobacco plants to } \\
\text { oxidative stress } \\
\text { Overexpressors performed better under drought. They } \\
\text { showed enhanced root growth and water stress tolerance }\end{array}$ & $\begin{array}{l}\text { Han et al. (2015) } \\
\text { Li et al. (2015a) }\end{array}$ \\
\hline TaEXPB23 & $\beta$-Expansin & Overexpression & $\begin{array}{l}\text { Longer internodes, larger leaf blades, more leaves, more } \\
\text { roots }\end{array}$ & Xing et al. (2009) \\
\hline$H v E X P B 1$ & $\beta$-Expansin & Promoter deletion & Shown to influence root hair formation & Won et al. (2010) \\
\hline AtEXLA2 & $\begin{array}{l}\text { Expansin- } \\
\text { like A }\end{array}$ & Overexpression & $\begin{array}{l}\text { Longer roots which were significantly longer than the wild } \\
\text { type roots }\end{array}$ & Boron et al. (2015) \\
\hline AtEXPLA2 & $\begin{array}{l}\text { Expansin- } \\
\text { like A }\end{array}$ & $\begin{array}{l}\text { Overexpression and } \\
\text { mutant lines }\end{array}$ & $\begin{array}{l}\text { Reduced EXLA2 transcript levels enhanced resistance to } \\
\text { necrotrophic pathogens (Botrytis cinerea; Alternaria } \\
\text { brassicicola) }\end{array}$ & Abuqamar et al. (2013) \\
\hline
\end{tabular}

The table shows expansin genes from several species affecting various stages of plant development from seed germination to fruiting as well as those affecting plant's response to environmental cues. It also shows the effects of manipulating expansin genes on plant growth using various molecular biology tools

Pp Prunus persica, Le/Sl Lycopersicon esculentum/Solanum lycopersicum L., At Arabidopsis thaliana, Ta Triticum aestivum, Gb Gossypium barbadense, Rh Rosa hybrid, Gm Glycine max, Os Oryza sativa, Ib Ipomoea batatas, Cs Cucumis sativus, Pn Populus nigra, Dz Durio zibethinus, Fa Fragaria x ananassa, Ma Musa acuminate

clade have almost similar effects on plant growth and development (Fig. 1). Although expansin studies have covered all the sub families, most of the studies have however focused a lot on the expansin A and B sub-families. Clades D and E in Fig. 1 consist of expansins from which have been shown to or are thought to act on internodes and roots, respectively while clade $\mathrm{F}$ mainly consists of expansins affecting either root or internode development. Clade A on the other hand consists mainly of those expansins which affect germination but it also contains other expansins affecting leaf development. Despite Clade $\mathrm{B}$ and $\mathrm{C}$ being mixed bags, it is clear that most of the genes in Clade B resulted in enhanced overall plant growth when overexpressed while Clade $\mathrm{C}$ consists of expansins affecting mainly leaf growth, seed germination and fruit ripening. This information is vital especially for future studies and crop improvement programs.
Besides affecting particular growth stages, expansins have also been shown to play a pivotal role in enhancing plant's ability to withstand biotic and abiotic stresses ( $\mathrm{Li}$ et al. 2011, 2013; Xu et al. 2014; Yan et al. 2014; Zörb et al. 2015).

\section{Effects of expansins on specific plant development stages from germination to fruiting}

\section{Effects on germination}

Germination is a process which is regulated by hormones such as ABA and GA which induces and breaks dormancy, respectively (Holdsworth and Soppe 2008). In general terms, it begins with imbibition which leads to the cracking of the seed coat thus allowing the radicle to emerge (Finch- 


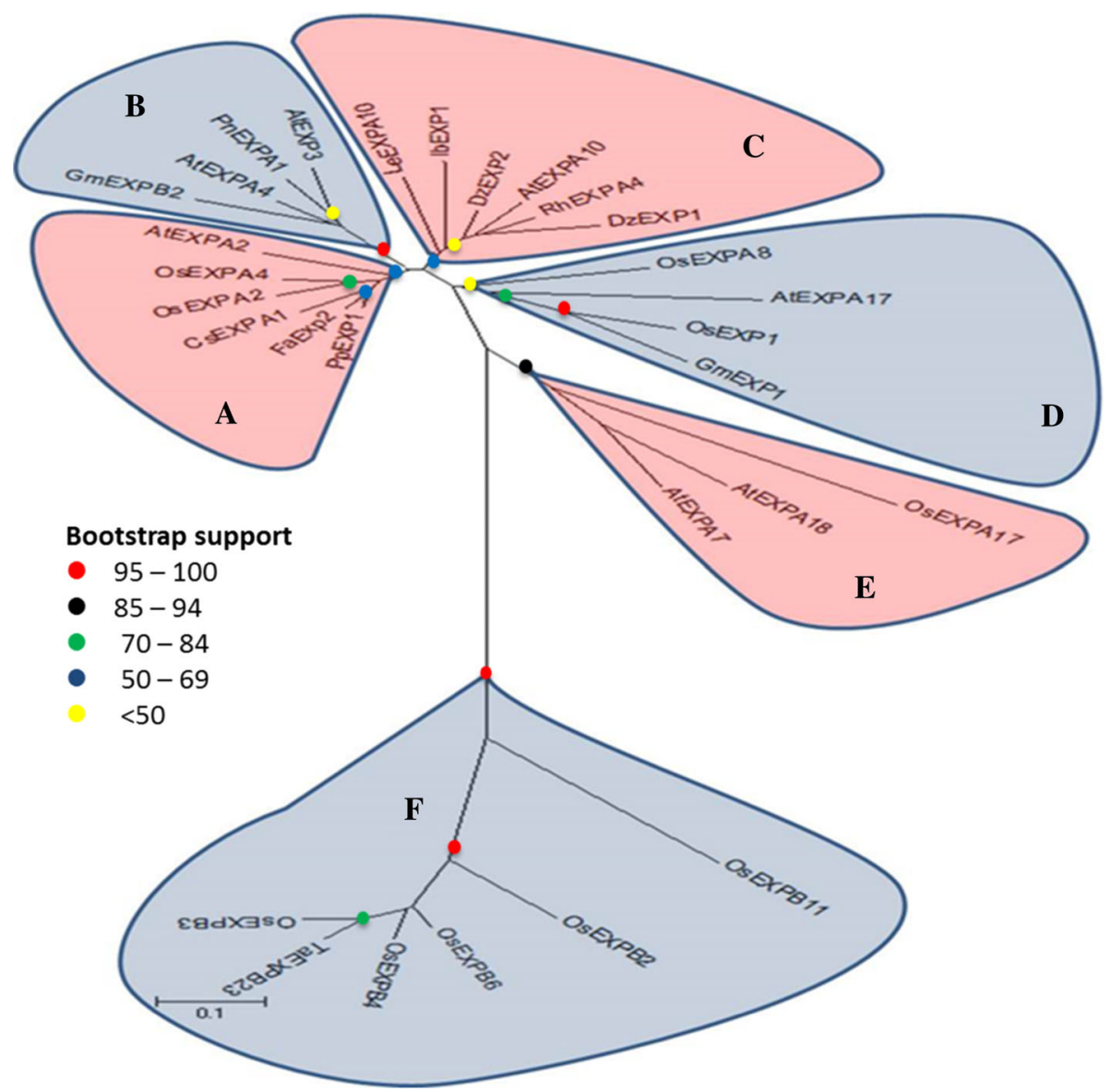

Fig. 1 Evolutionary relationship of 29 selected expansin genes and their effect on plant growth. These genes were selected based on the fact that they are phylogenetically and functionally related. Clades $D$ and $E$ consist of expansins which have been shown to or are thought to act on internodes and roots respectively while clade $F$ consists of expansins affecting either root or internode development. Clade $A$ on the other hand consists mainly of those expansins affecting germination but it also contains other expansins affecting leaf development. Most of the genes in Clade $B$ enhanced overall

savage and Leubner-metzger 2006). The various aspects of seed dormancy and germination and related molecular networks have been extensively reviewed (Finch-savage and Leubner-metzger 2006; Holdsworth and Soppe 2008). For farmers, it is usually encouraged to use seeds with a higher germination percentage which will encourage uniform seedling emergence since this will have in most cases a direct bearing on costs and yield among other parameters.

During the early phases of germination, the seed undergoes a lot of transcriptional changes of key metabolic enzymes and several expansins are induced (Weitbrecht et al. 2011). Some of these expansins such as the tomato expansin LeEXPA8 for example, are only expressed in germinating seeds (Chen et al. 2001). Expansins such as AtEXPA1, -2, -8, and -9 (Morris et al. 2011; Weitbrecht et al. 2011; Yan et al. 2014), LeEXPA8 and LeEXPA10 plant growth when overexpressed while Clade $C$ consists of expansins affecting mainly leaf growth, seed germination and fruit ripening. The evolutionary history was inferred using the neighbor-joining method with 500 bootstrap replicates. The optimal tree with the sum of branch length $=5.85540671$ is shown. The evolutionary distances were computed using the Poisson correction method and are in the units of the number of amino acid substitutions per site. Evolutionary analyses were conducted in MEGA6

(Chen et al. 2001) and OsEXPA1 and OsEXPA2 (Huang et al. 2000) are also believed to play important roles during seed germination. Messenger RNA expression analysis have demonstrated that seed germination coincides with strong expression of these expansins thus supporting the hypothesis that expansins play important roles in endosperm-mediated processes during early germination that lead to and control testa rupture. This notion has been supported by Lü et al. (2013) who reported that after overexpressing RhEXPA4, a rose expansin gene in Arabidopsis, the germination percentage of transgenic Arabidopsis seeds was higher than that of wild type seeds even under salt stress and ABA treatments. This was further supported by Yan et al. (2014) who also demonstrated that overexpression of AtEXPA2 hastened germination while its suppression significantly delayed it. Yan et al. (2014) also 
demonstrated that $A t E X P 2$ is likely to control seed germination through GA signaling.

Although the details of expansin action on germination are not yet clear, the need for cell wall loosening and the involvement of expansins during germination have been endorsed by Voegele et al. (2011) who suggested that AtEXPA9 is involved in micropylar endosperm weakening and in radicle growth in Arabidopsis. These researchers confirmed the importance of cell wall loosening in many plant developmental stages including seed germination where radicle growth and endosperm weakening take place (Voegele et al. 2011). In a separate study, this AtEXPA9 was also reported to be involved in seed germination together with AtEXPA2 and AtEXPA7 (Morris et al. 2011). Recent studies have also reported that atexpb2 mutant plants showed a significantly lower germination rate than the wild type plants under different levels of Methyl viologen (oxidative stress) treatment thus suggesting that expansin proteins are involved in oxidative stress tolerance as well (Han et al. 2015).

With this information at hand, one can easily conclude that expansins are indeed important during seed germination. Combined with other methods, such expansins can be a useful tool in enhancing this process and improving the ability of the seed to germinate under various conditions. Such conditions include salinity which is fast becoming a common problem affecting crop production.

\section{Effects on root development and growth}

Besides anchorage, plant roots play other crucial roles which include nutrient and water uptake thus a vigorous root system is needed since it will generally result in a better plant. The expression of the $\beta$-expansin gene $H v E X P B l$ was demonstrated to be root hair-specific and associated with root hair formation in barley (Kwasniewski and Szarejko 2006; Won et al. 2010). HvEXPBI gene contains five root hair-specific cis-elements (RHEs) in its promoter region (Kwasniewski and Szarejko 2006) and it has been confirmed that these RHEs play vital roles in cell wall modification during root hair morphogenesis (Won et al. 2010).

Several other expansins have also been shown to influence root development and growth. These include GmEXP1, a root specific $\alpha$-expansin (Lee et al. 2003) which was found to accelerate root growth when ectopically expressed (Guo et al. 2011). Besides enhancing the overall plant growth when overexpressed, GmEXPB2, another expansin gene from soybean, was also found to be involved in root hair elongation (Guo et al. 2011). Using quantitative real-time PCR technique to evaluate the temporal and spatial expression patterns of GmEXPB2, Guo et al. (2011) found out that its expression occurred primarily in the roots and was up-regulated by abiotic stresses including water, phosphate $(\mathrm{Pi})$ and iron $(\mathrm{Fe})$ deficiency. It was also reported that overexpression of RhEXPA4, a rose expansin gene resulted in transgenic Arabidopsis plants with more lateral roots (Lü et al. 2013). An almost similar report showed that transgenic plants overexpressing TaEXPB23 exhibited higher fresh weight and longer primary root than wild types under oxidative stress (Han et al. 2015).

Through loss-of-function studies using the RNA interference approach together with gain-of-function studies, several other expansins have been shown to promote and facilitate root initiation, root hair initiation and lateral root emergence in plants. Compared to their wild type counterparts, plants with knocked down AtEXPA17 exhibited reduced lateral root formation while overexpressors of the same gene showed enhanced lateral root formation in transgenic Arabidopsis (Lee and Kim 2013). The same trend was reported in rice when $O S E X P B 2$ was silenced (Zou et al. 2015). Silencing OsEXPB2 was shown to affect root system architecture by inhibiting cell growth. Many other expansin genes have also proved to play important roles during root development and growth. Such expansins include TaEXPB23 which has been shown to significantly increase root network and root biomass when overexpressed ( $\mathrm{Li}$ et al. 2015a; Xing et al. 2009), OsEXPA17 which has been reported to influence rice root development (Yu et al. 2011), AtEXPA7 and AtEXPA18 which have been shown to play crucial roles during root hair initiation and root growth in Arabidopsis (Cho and Cosgrove 2002) and AtEXP4 (Lee and Kim 2013). Recent studies have also shown that overexpression of AtEXLA2, a member of the expansin-like sub-family resulted in roots which were significantly longer than those of the wild type (Boron et al. 2015).

Although the clear mode of action of expansin on root development and growth is not clear as yet, it has been demonstrated that expansins accelerate cell growth and expansion when exogenously applied to isolated living cells (Cho and Cosgrove 2000). It is also known that expansins increase the cell wall flexibility through loosening and softening cell walls thus enabling necessary tissue modification. This and other related knowledge can be put together and included in crop improvement programs. Although most desired crop traits are controlled by many genes, inclusion of certain expansins in the breeding programs can produce beneficial effects. It has been shown that overexpression of $G m E X P B 2$ enhances root growth under stress conditions (Guo et al. 2011) thus presenting a possibilty to improve crops for specific regions. Besides enhancing rice and soybean root systems, GmEXPB2 and OsEXPB2 have been reported to enhance the plants' ability to tolerate abiotic stresses. If such expansins are employed 
in breeding programs, it is likely that these crops will be significantly improved.

\section{Effects on leaf initiation and leaf growth}

Leaves act as the manufacturing industries for the plant and animals. The process of leaf development is complex and influenced by many factors including hormones and genes such as expansins. According to Green (1999), a new leaf emerges in the region of reduced tension, which he reported to be surrounded by a circular zone of elevated tension. He pointed out that the tissue tension depends on mechanical properties of cell walls and therefore among other things, we can assume the involvement of expansins since they have been reported to influence the mechanical properties of the cell walls. Green (1999) further pointed out that the leaf primordium is initiated in the site of the peripheral region of apical dome where the cell wall extensibility is elevated.

This elevated extensibility of the cell wall could be a result of expansin action. A follow up study by Pien et al. (2001) confirmed that indeed expansins are involved during leaf initiation. They reported that when CSEXPAl expression was ectopically induced, it initiated development of the leaf primordium, which later developed into a normal leaf. In their study with tetracycline-induced expansin expression, they also found that local application of the tetracycline-containing paste at early stages of new primordium development was effective for the induction of a lobe on a leaf blade thus supporting the hypothesis that expansin play an important role during leaf development.

Several later studies have confirmed and demonstrated that expansins play an important role during leaf initiation and growth. Using a special method that allowed transient local micro-induction of gene expression in transgenic plants, Pien et al. (2001) tested the possible function of expansins in leaf morphogenesis. Results from their study confirmed the earlier notions as it showed that local expression of expansins within the meristem induces a developmental program that recapitulates the entire process of leaf formation. Many other studies have also demonstrated that overexpression or suppression of expansin genes can positively or negatively affect the process of leaf development, respectively. Using quantitative real-time PCR technique to evaluate the expression patterns of AtEXP10, Cho and Cosgrove (2000) demonstrated that there was much greater AtEXP1O expression in young growing petioles and leaf blades than in older non-growing leaves which highlights the significance of expansin genes during the process of leaf initiation and development. Overexpression and suppression studies of this expansin gene revealed that leaf size was substantially reduced in antisense lines while its overexpression resulted in plants with somewhat larger leaves (Cho and Cosgrove 2000). Also, AtEXPA10 and PnEXPAl were reported to significantly affect tobacco leaf cell sizes resulting in larger leaves when overexpressed (Kuluev et al. 2012, 2013). This clearly supports the idea that AtEXP10 functions in the control of leaf size through its action on cell-wall rheology.

Recent studies have concluded that expansins are involved in wheat leaf growth. Zhou et al. (2015) reported that expansin activity was associated with the relative elongation rate of leaves during leaf development. Other related examples include the suppression of $O S E X P B 2$ in rice which resulted in significant physiological changes including a significant reduction in the width of leaf blades (Zou et al. 2015) and overexpression of IbEXPI which resulted in transgenic plants with more rosette leaves (Bae et al. 2014).

Also, abiotic factors like vapour pressure deficit can negatively affect the expansion of the leaf through their effect on expansin expression. They have been reported to down-regulate the transcript level of expansin genes thus affecting cell extensibility which consequently reduces leaf growth and development (Devi et al. 2015). All this demonstrates the involvement of expansins in leaf development thus we can speculate that combined with other breeding strategies, these expansins presents an opportunity for scientists to improve fodder and other crops whose leaves are of economic importance. This can also see yield increase due to enhanced light interception which will allow for increased photosynthesis.

\section{Stomata opening and closing}

Features such as trichomes and stomata play vital roles in enabling plants to adopt and thrive in their environments. The opening and closing of stomata is strictly regulated by various intracellular and extracellular factors in response to environmental cues (Wei et al. 2011a, b). Guard cell expressed expansins, AtEXPAI and VfEXPAl regulate stomatal opening by altering the structure of the guard cell wall (Wei et al. 2011a, b). Overexpression of these expansins in Arabidopsis and tobacco plants respectively increased the rate of light-induced stomatal opening, while their inhibition reduced the sensitivity of stomata to the same stimuli (Wei et al. 2011a, b). These researchers also reported an increase in transpiration and photosynthesis rate in overexpressors of these genes which was almost double that of the wild type plants. This led them into concluding that expansins participate in the regulation of stomatal movement by modifying the cell walls of guard cells basing on the fact that wall loosening, which is controlled by expansins, is essential for guard cell expansion and constriction. 
It has also been noted that under drought conditions, $R h E X P A 4$ overexpression has the potential to enhance the survival rate of the transgenic plants (Lü et al. 2013). Lü et al. (2013) concluded that among other probable causes, enhanced drought tolerance of $35 S:: R h E X P A 4$ plants was partially a result of decreased stomatal density due to leaf modifications in RhEXPA4 overexpressors. These overexpressors developed smaller rosette size with compact epidermal cells, indicating that RhEXPA4 improves drought tolerance by modulating leaf growth. All these recent findings are in line with Sampedro and Cosgrove (2005) who hypothesized that the overexpression of expansin might disrupt the elaborate microtubule arrays, cellulose deposition and cell-wall thickening that are required for the development of stomatal guard cells and their adjacent cells during stomatal morphogenesis thus resulting in altered leaf morphology.

One strategy through which plants acclimatize or adapt to drought is through reducing transpirational water loss. Stomatal closure or lower stomatal density has been mentioned among the earliest responses to drought stress (Chaves et al. 2003). Combined with other tools, expansins such as RhEXPA4 and AtEXPl can be useful crop improvement tools in this regard considering the current challenges that crop production is facing.

\section{Effects on stem elongation}

After emerging from the soil, most of the plants must have a mechanism that enables them to increase their stem sizes before they can start bearing fruits. Although wheat breeding programs have favored shorter varieties because of their ability to withstand lodging, the need for longer stems or the ability to develop them when the need arises might be very important in crops like rice which are usually grown on lowlands and thus prone to flooding.

Catling et al. (1988) outlined that although rice has a good reputation for growing well under flooded conditions, it should however possess the ability to escape aerobically from rising water to maintain the apical parts above water. This is very important or else the results will be fatal. Some rice varieties have the ability to accelerate stem elongation in response to flooding environment. After reports of unbelievable rice stem elongation rates of up to $25 \mathrm{~cm}$ per day (Lee and Kende 2002), several researcher focused their attention on rice stem elongation. Most of them reported the involvement of expansins (Cho and Kende 1997a, b; Choi et al. 2003; Zou et al. 2015).

Following a report by Cho and Kende (1997b) which stated that the expression of OsEXPA2 and OsEXPA4 was induced by submergence and treatment with gibberellin, crop scientists wanted to learn more about the involvement of expansins in rice stem elongation. This saw several expansin genes including OsEXPB3, OsEXPB4, OsEXPB6, and $O s E X P B 11$ being implicated in rice stem elongation (Lee and Kende 2001). Although the exact mode of action is still not clear, it is generally agreed and hypothesized that expansins break the hydrogen bonds between cellulose microfibers and cross-linking matrix glycans, resulting in slippage between cell walls (Zou et al. 2015). This enables cells to expand while allowing tissues to differentiate and grow accordingly and in this case thus stem elongation.

Choi et al. (2003) concurred with Lee and Kende (2001) and demonstrated that expansins such as OsEXP4 affects rice stem sizes. Even though overexpression of OsEXP4 resulted in pleiotropy, their results showed that overexpressors carrying a single copy of the gene grew taller than control plants and developed some additional leaves while the antisense plants were shorter than the average control plants (Choi et al. 2003). This action of expansin is consistent with findings reported by Zou et al. (2015) who noted a decrease in plant height of RNAi lines where expansins were suppressed. Zou et al. (2015) also showed that wild type plants were taller than the RNAi lines by almost $12 \mathrm{~cm}$ thus confirming the involvement of expansin in stem development and elongation. Besides affecting stems, expansins also affect coleoptile and mesocotyl lengths. OsEXP4 overexpressors demonstrated a 31 and $97 \%$ increase in coleoptile and mesocotyl length, respectively while in antisense plants, a 28 and $43 \%$ decrease, respectively was noted (Choi et al. 2003). This change can be attributed to the reported increase in average cell length which increased by up to $58 \%$ in the mesocotyls of lines overexpressing OsEXP4 while it decreased by $22 \%$ in the antisense transgenic lines (Choi et al. 2003). It was also shown that this change in cell length was due to increased and decreased coleoptile cell wall extensibility of sense and antisense transgenic lines, respectively. Cell wall extensibility of coleoptiles from sense transgenic lines increased by up to $32 \%$ while that of antisense transgenic lines decreased by up to $20 \%$ (Choi et al. 2003). These reports have been recently supported by Boron et al. (2015) who reported that AtEXLA2 overexpression decreased the wall strength in Arabidopsis hypocotyls consequently resulting in transgenic plants with significantly longer hypocotyls than in wild type plants.

In short, it has been demonstrated that several expansins (Table 1) have the potential to alter plant cell wall extensibility and subsequently influence stem growth and development through the hypothesized mode of action. With all this information, crop scientist might consider including expansin in their breeding programs. Wheat breeders for example have been screening for genotypes with longer coleoptile lengths. The coleoptile is essential for successful emergence and early plant vigour (Farhad 2014). Plants with longer coleoptiles can be sown deeper 
and this allows growers to exploit soil moisture lying below the drying topsoil. Deeper sowing also assists in reducing removal of seeds by birds and rodents and in avoiding phytotoxicity associated with some pre-emergent herbicides (Farhad 2014). Overexpression of OsEXP4 was shown to significantly increase coleoptile and mesocotyl length by a massive 31 and $97 \%$, respectively (Choi et al. 2003) as described above. This shows that if properly integrated into breeding programs, expansins can be a useful tool.

\section{Expansin and reproduction}

Several expansins are predominantly expressed in the plant reproductive organs. A number of different $\alpha$-expansins are expressed during floral elongation, opening and senescence in Mirabilis jalapa (Dai et al. 2012; Gookin et al. 2003). It is likely that these expansins affect these reproductive growth phases. Dramatic changes in expansin transcript abundance during the rapid expansion and subsequent senescence of the ephemeral flowers suggests that expansins are involved during this period and are thought to play a pivotal role in influencing flower growth and senescence (Gookin et al. 2003). Dai et al. (2012) demonstrated that silencing and overexpressing RhEXPA4, a rose expansin, affected expansion and dehydration tolerance of rose petals. In a similar report, the expression of an $\alpha$-expansin CPEXP1 was shown to be directly related to the development of winter sweet flowers (Ma et al. 2012). This expression showed an almost similar pattern with the expression of gladiolus $\alpha$-expansin GgEXPAl (Azeez et al. 2010). Real-time PCR results showed that the transcript level of the CPEXPI gene in flower buds gradually increased in the early stages of flower development until a peak was reached before it showed a drastic reduction in the final stages of flower development. This leaves us speculating that manipulation of such expansin genes can benefit agricultural sectors like floriculture and horticulture at large.

On the other hand, pollination is a very important part of the reproduction phase in flowering plants. Although not many studies have been done to elucidate the role played by these expansins during pollination (Lausser et al. 2010), pollen tube development and fertilization, several $\beta$-expansins have however been reported in rice pollen grains (Dai et al. 2007) and maize pollen grains (Kapu and Cosgrove, 2010; Li et al. 2003a; Valdivia et al. 2006, 2007, 2009). It is believed that these expansins play important roles which include among other things softening the stigma cell walls. This is thought to facilitate and enable penetration and growth of the pollen tube since it must overcome the resistance on the stigma surface, a problem that any other foreign pollen tube or other intruder must face thus protecting the plant from foreign pollen grains and potential pathogens.

This idea has been supported by some researchers who have speculated that by breaking the cellulose-hemicellulose hydrogen bonds of these reproductive structures, the expansins facilitate this penetration by softening the stigma and underlying cell walls (Mollet et al. 2013). The need for stigma cell wall loosening and softening has led researchers to conclude that there is a possibility of the involvement of expansins during pollen tube development and fertilization (Mollet et al. 2013). This idea has been supported by the discovery of AtEXPA4 and AtEXPB5 which are strongly expressed in dry pollen grains, during pollen imbibition and during pollen tube growth. Several other expansins which are expressed on the stigma and ovary of Arabidopsis have also been reported (Mollet et al. 2013).

ZmEXPB1 is a maize pollen expansin which has also been linked with an in vivo wall-loosening function which facilitates pollen tube penetration into maize silk and growth through them (Valdivia et al. 2007). It was noted that silks continued to elongate for longer periods after pollination in the mutant lines lacking the protein coded by this expansin gene (Valdivia et al. 2006, 2007). Valdivia et al. (2009) showed that emerging pollen tubes from pollen deficient in this $\beta$-expansin gene had difficulties entering the silk. Kapu and Cosgrove (2010) also reported on this maize expansin and propounded that such specific silk expansins may facilitate pollen tube growth by loosening the maternal cell walls. They however dismissed the hypothesis that silk growth inhibition was associated with a down-regulation of expansin abundance and/or activity which resulted in rigidification of the silk cell walls. They pointed out that cell wall rigidification may occur by a number of mechanisms including the coupling of feruloyl side chains attached to wall polysaccharides, formation of isodityrosine links, and the strengthening of pectin-calcium networks.

Zhang et al. (2014) found that out of the 88 maize expansin genes (ZmEXPs), at least 21 were predominantly expressed in reproductive organs. These authors reported that $16 \mathrm{ZmEXPs}$ were predominantly expressed in the tassels while $5 \mathrm{ZmEXPs}$ were predominantly expressed in the endosperm suggesting their involvement in endosperm development. If these expansins play an important role during the development of the endosperm, they might be a useful tool worth adopting. The endosperm is an important seed component which occupies a huge part of the seed hence integrating these expansins with other maize breeding tools might increase the yield.

All these studies support the hypothesis that expansins are involved during reproduction. They have been endorsed by recent knowledge which outlines the involvement of expansins during this growth stage and states that 
expansins solubilize the middle lamella and facilitate cell separation which then aids invasion of the maternal tissues (Georgelis et al. 2015).

\section{Effects on fruit ripening and softening}

Hormones and the environment play a crucial role on the growth and development of plants. Ethylene, a ripening hormone, influences the transcription level of LeEXPA1, a tomato expansin and there is a positive correlation between LeEXPA1 level and tomato fruit softening (Rose et al. 1997). It is thought that through the reported action of expansins on cell wall, this ripening-regulated expansin expression is likely to contribute to cell wall polymer disassembly which results in fruit softening by increasing access of specific cell wall polymers to hydrolase action (Rose and Bennett 1999). The role of expansins on fruit ripening has been recently endorsed by Minoia et al. (2015) who concurred with the idea that the expansins that are highly expressed during tomato fruit ripening contribute to the fruit softening. Minoia et al. (2015) demonstrated that mutations in $\alpha$-expansin SlExpl gene increased fruit firmness. They reported a 41 and $46 \%$ fruit firmness enhancement in Slexp1-6 and Slexp1-7 mutant lines, respectively as compared to the control plants.

Xyloglucan disassembly has been implicated as an early event in fruit softening but enzymatic basis for xyloglucan depolymerization is not well established. However, Rose and Bennett (1999) hypothesized that xyloglucan metabolism may be regulated by substrate accessibility and expansins have been proposed to mediate enzymatic accessibility of this substrate in ripening fruit. This is in line with reported effects of the tomato Expl (Brummell et al. 1999). Since softening of tomato fruit during ripening is accompanied by alterations in both the architecture and physicochemical properties of the cell wall, and in the polymers of which it is composed, overexpression of this expansin gene (tomato Expl) has been shown to hasten the softening process (Brummell et al. 1999). The tomato Expl expression was correlated with fruit cell wall hemicellulose depolymerization and fruit softening, typical of ripe fruit, even in mature green fruit before the commencement of ripening (Brummell et al. 1999). This concurs with the observation that in the mutant lines that did not express LeEXPAl expansin gene, the tomato fruits remained green and firm (Rose et al. 2000) and is further supported by the recent reports which states that Slexpl mutant lines remained firm for longer periods than the wild type tomato plants (Minoia et al. 2015).

Several ripening related expansins have been reported in strawberries (Civello et al. 1999; Harrison et al. 2001). FaEXP2 is one example of such expansin genes which is predominantly expressed in strawberry fruits. Its expression has been shown to increase in ripening strawberry fruits (Civello et al. 1999). This points out at its involvement during the ripening process and this has been further supported by Brummell et al. (1999). In durian fruits (Durio zibethinus), DzEXP1 and DzEXP2 expression is also positively correlated with durian fruit softening suggesting that these expansins are involved during durian fruit ripening and have been shown to affect peel dehiscence and softening of the fruit pulp (Palapol et al. 2015).

Recent studies have reported ripening related expansins in Vasconcellea pubescens and Magnolia grandiflora fruits (Gaete-Eastman et al. 2015; Lovisetto et al. 2015). $V p E X P A 2$ is an $\alpha$-expansin which has been implicated in softening of Vasconcellea pubescens fruits (Gaete-Eastman et al. 2015) while $M g E X P 1$ and $M g E X P 2$ have been implicated in Magnolia grandiflora softening with MgEXP2 reported to show a more ripening-related expression (Lovisetto et al. 2015). $M g E X P 2$ had low transcripts in young growing tissues peaking in the ripe red sarcotesta (Lovisetto et al. 2015), indicating its possible involvement in tissue softening. Several other expansins affecting ripening have been reported in many other crops including peach (Hayama et al. 2000) and banana (Trivedi and Nath 2004).

Breeding for improved fruit shelf life is still a major target for most horticultural crop including tomatoes. The above studies led to the conclusion that expansins play a significant role during fruit ripening and softening. Considering the current huge post-harvest losses being experienced, this knowledge can be used to develop new alleles in different components of the fruit softening pathways which will likely extend breeder's tool box to improve tomato shelf life for example. This could be useful in breeding programs in combination with other alleles in the antioxidant or ethylene pathway especially when one considers that many of earlier investigations that focused on the manipulation of the polyamine or anthocyanin pathways had deleterious consequences on fruit quality traits such as flavor, texture and aroma despite their contribution in delaying fruit softening (Lovisetto et al. 2015).

\section{Effects on crop yield}

Bae et al. (2014) summarized a number of studies which showed that seed size was altered when the transcript level of the seed development-related genes were modulated. Such genes include expansins which have been implicated in affecting seed development and seed size (Bae et al. 2014; Kuluev et al. 2012). Seed size is one of the traits that breeders are always trying to improve. When a sweet potato $\beta$-expansin gene (IbEXPl) was overexpressed in Arabidopsis under the control of the cauliflower mosaic $35 \mathrm{~S}$ promoter, it enhanced plant growth rate (Bae et al. 2014). Most importantly, overexpression of this gene 
resulted in plants with thicker siliques and produced seeds which were significantly larger than those from Col-0 plants (Bae et al. 2014). Interestingly, these large seeds accumulated more proteins and starch than their control counterparts. In short, the IbEXP 1 overexpressors produced more inflorescence stems and siliques than control plants which led to a 2.1-2.5 fold increase in total seed yield per plant (Bae et al. 2014). An almost similar trend was observed when AtEXPA10 and PnEXPAl genes were overexpressed in tobacco (Kuluev et al. 2012). Overexpression of these expansin genes in tobacco resulted in the tobacco plants producing larger leaves and larger flowers which weighed more than their wild type counterparts (Kuluev et al. 2012).

Expansins do not only affect seed yield, they also have the ability to affect other types of yield which might not necessarily be grain. For example, in cases where tubers are the harvested yield, expansins have been reported to increase the sizes of these tubers (Noh et al. 2013). Messenger RNA expression analysis suggests that expansins might also influence the growth of the cotton fibers (Shimizu et al. 1997). This notion is supported by the presence of GhEXPl (Harmer et al. 2002; Shimizu et al. 1997), GbEXPA2 and GbEXPATR (Li et al. 2015c) expansin genes which are predominantly expressed in the cotton fibers where they are thought to play an important role in cell wall loosening during fiber elongation (Harmer et al. 2002). Recent expression analysis, RNAi and overexpression studies have revealed that indeed cotton $\alpha$-expansin play a significant role in fiber development ( $\mathrm{Li}$ et al. 2015c). It has been demonstrated that besides enhancing root hair development in transgenic Arabidopsis, GbEXPATR overexpression enhanced cotton fiber length, fineness and strength (Li et al. 2015c).

It can therefore be concluded that even though yield is a quantitative trait, expansins can be a useful tool to manipulate yield of many different crops. However, there are some exceptions, for example overexpression of RhEXPA4 at high levels in Arabidopsis affected fertility, resulting in a reduced number of inflorescences and flowers which subsequently resulted in an $80 \%$ loss in seed production (Lü et al. 2013). There is therefore a need for further research in this area.

\section{Effects on biotic and abiotic stress tolerance}

Just like any other plant, during desiccation the resurrection plant (Craterostigma plantagineum) employs many of the protective mechanisms such as the accumulation of sugars and protective proteins (Hoekstra et al. 2001). However, this plant has demonstrated an outstanding ability to survive extreme cases of desiccation which usually result in the death of most other plants. How does it achieve this?
It has been noted that in resurrection plants, cell wall extensibility increased markedly in the leaves during drying and this coincided with an increase in expansin activity (Jones and McQueen-Mason 2004). These researchers noted that transcript abundance for expansin genes correlated closely with the dehydration and rehydration events in the resurrection plant and they concluded that expansins play a key role in enabling desiccation tolerance in this plant. Several studies have provided evidence that expansins are associated with environmental stress tolerance in plants. This idea has been supported by Zhao et al. (2011) who reported enhanced drought tolerance in wheat varieties overexpressing expansin genes. Li et al. (2011) who was in agreement with this idea pointed out that transgenic tobacco lines overexpressing TaEXPB23 driven by the constitutive $35 \mathrm{~S}$ cauliflower mosaic virus (CaMV) promoter lost water more slowly than the wild-type plants under drought stress. It was further supported by ( $\mathrm{Li}$ et al. 2013) who showed that when the same expansin gene, TaEXPB23, was expressed in tobacco plants under the control of the stress-inducible promoter RD29A, the transgenic plants became more tolerant to water stress than their wild type counterparts.

Abiotic stresses, such as drought, cold and salinity result in the production and accumulation of reactive oxygen species (ROS). These are highly reactive and toxic to plant cells. TaEXPB23 has been reported to influence the activity of antioxidant enzymes: in particular, the activity of the cell wall-bound peroxidase (Han et al. 2015). Han et al. (2015) showed that overexpression of TaEXPB23 improved the tolerance of transgenic tobacco plants to oxidative stress. This is in line with earlier reports by Abuqamar et al. (2013) who reported an enhanced tolerance to phytoprostance $\mathrm{A}_{1}$ in Atexpla2 mutant lines. Other recent studies have concluded that expansins are involved in wheat response to water stress (Zhou et al. 2015) thus endorsing the idea that expansins play a key role in enabling drought tolerance in plants.

Heat and salt stress are both detrimental abiotic stresses that can cause serious damage to crops. However, expansins can enhance the plant's ability to withstand such stress as shown by various studies. Overexpressing the $\alpha$-expansin gene PpEXP1 from Poa pratensis in tobacco plants produced transgenic plants which exhibited a less structural damage under heat stress (Xu et al. 2014). These transgenic plants showed lower electrolyte leakage, lower levels of membrane lipid peroxidation, and lower content of hydrogen peroxide. On the other hand, they also showed a higher chlorophyll content, a higher net photosynthetic rate, a higher relative water content, a higher activity of antioxidant enzyme and a higher seed germination rate compared to the wild-type plants (Xu et al. 2014). This effect of PpEXP1 is almost similar to the effect of 
RhEXPA4 which among many other things conferred abiotic stress tolerance when overexpressed in Arabidopsis (Lü et al. 2013). Overexpressors of RhEXPA4 exhibit multiple modifications in their leaf blade epidermal structure which included smaller, compact cells and fewer stomata on leaves. It is likely that these modifications which are thought to be brought about by the action of expansins enabled the plants to be tolerant to the abiotic stresses such as drought and salt stress (Lü et al. 2013). Latest reports support the hypothesis that expansins are involved in conferring plant salt tolerance. It has been revealed that salt sensitive maize had reduced $\beta$-expansin protein while on the other hand, maintenance of the $\beta$ expansin protein is thought to have contributed to the better expansion capacity of the epidermal cell walls of the more resistant maize under salt stress (Zörb et al. 2015). This led to the conclusion that down regulation of the growth-mediating $\beta$-expansins reduced the expansion capacity of epidermal cells in the salt sensitive maize hybrid (Zörb et al. 2015).

Several other expansins have the ability to influence plant's response to stress. When knocked down, AtEXPA2 mutants showed a higher sensitivity to salt stress and osmotic stress while the opposite was true with the overexpressors of the same expansin gene (Yan et al. 2014). It is also thought that the increase in the level of CpEXP1 observed in zucchini fruit under cold stress plays a significant role in improving chilling injury tolerance during postharvest cold storage in zucchini fruit (Carvajal et al. 2015). This concurs with Bauerfeind et al. (2015) who concluded that the expansin from their experiment appeared to act more as a counterbalancing agent against the growth-depressing effects of chilling exposure than as a mere growth promoter (Bauerfeind et al. 2015).

Although most studies support the notion that expansins enhances plant's tolerance to abiotic stress, Kwon et al. (2008) opposed this notion. Yan et al. (2014) stated that overexpression of AtEXPA2 gene enhanced salt tolerance and this was recently supported by Geilfus et al. (2015) who outlined that expansins have the ability to restore growth on growth reduced leaves under salt stress. However, after ectopically expressing some expansin genes, Kwon et al. (2008) reported that AtEXP3 and AtEXPB1 overexpressors became very sensitive to salt stress. There is therefore a need for further exploration of this area. Despite this, these researchers were in agreement with other researchers on the effects of expansins in enhancing growth and increasing leaf and petiole sizes through their effect on cell wall which enables plants to develop larger cells.

Expansins can also improve nutrient absorption from the soil. Studies have demonstrated that nutrient deficiency can stimulate the expression of expansins which will improve the plant's root system and subsequently its ability to absorb nutrients such as phosphorus (P) from the soil even under low P levels (Guo et al. 2011; Li et al. 2014). This idea was recently endorsed by Zhou et al. (2014) when they overexpressed GmEXPB2 in soybean and observed an increase in phosphorus efficiency. Li et al. (2015a) also concurred with this notion. They reported an increase in root network in overexpressors of the expansin gene TaEXPB23 under the root-specific promoter PYK10. These transgenic plants showed an increased water uptake and performed better under drought probably because of the increased root to shoot ratio. All this is in line with the conclusion drawn by Li et al. (2014) who concurred with the idea that expansin proteins are involved in altered plant growth and development under nutrient stress conditions. They also postulated that the roles of expansins involved in this regard vary according to the nutrient and the particular expansin involved. This was after they observed that GmEXPB2 was highly induced by phosphorus deficiencies treatment (Li et al. 2014), which is consistent with previous results (Guo et al. 2011) while several other different GmEXPBs also responded to different deficiencies including nitrogen, phosphorus, potassium and iron deficiencies (Li et al. 2014).

Even though there is a lot of evidence supporting the idea that expansins enhance plants' tolerance to biotic and abiotic stress, there is need to validate this. This area is very important considering that a lot of the cultivated soils are becoming saline and less fertile while on the other hand heat stress and drought among other things are inevitable due to global warming and climate change. Inclusion of expansins such as GmEXPB2 and TaEXPB23 into breeding programs can enhance plants' performance under nutrient limited conditions and drought conditions, respectively for example.

Plant diseases cause huge crop losses annually. It has been demonstrated that overexpression of the P450 gene CYP71Z2 in rice confers some resistance to the bacterial blight (Li et al. 2015b), which is partially contributed by the suppression of three rice $\alpha$-expansin genes (EXPA1, EXPA5 and EXPA10) and three rice $\beta$-expansin genes (EXPB3, EXPB4 and EXPB7). This conclusion is in line with the notion which was propounded by Ding et al. (2008). They stated that suppression of expansion genes can prevent plant cell walls from loosening resulting in enhanced physical protection of plants against phytopathogens. This idea of suppressing expansins to enhance disease tolerance has been supported by Abuqamar et al. (2013) who reported an enhanced resistance to the necrotrophic fungi Alternaria brassicicola in Atexpla2 mutant lines. This discovery is again an important starting point towards improved breeding for resistance to phytopathogens. 
In areas where the parasitic weed striga (Striga asiatica) is present, it is a menace to farmers. However, before the plant-striga parasitism relationship is established, a haustorium must be formed. O'Malley and Lynn (2000) outlined that the process of haustorial organogenesis involves rapid arrest of root elongation, a redirection of cellular expansion from longitudinal to radial dimensions in the cells just distal to the root tip and the development and growth of haustorial hairs centrifugal to the swelling root tip. Since expansins are actively involved during cell expansion and haustorial development is critically dependent on cellular expansion, it is thought that expansins play a crucial role during this process. This has been confirmed by the identification of SaExp1, SaExp2 and SaExp3, whose expression drastically increases during haustorium formation (O'Malley and Lynn 2000).

On the other hand, nematodes are obligatory biotrophic endoparasites which invade host roots and induce formation of syncytia, structures that serve them as the only source of nutrients. Just like haustorial organogenesis described above, syncytium development is characterized by extensive cell wall modifications (Fudali et al. 2008a, b). It is hypothesized that nematodes change expression of plant genes encoding cell wall modifying proteins including expansins (Fudali et al. 2008b). These researchers showed that two $\alpha$-expansin genes (LeEXPA4 and LeEXPA5) were up regulated in tomato roots infected with potato cyst nematode (Globodera rostochiensis). This is inline with earlier studies (Ithal et al. 2007; Klink et al. 2007) in which microarray experiments revealed that expansin genes EXPL2 and EXPR3 were up-regulated in soybean roots infected with soybean cyst nematode (Heterodera glycines). Fudali et al. (2008b) also demonstrated that the cyst nematode development on transgenic plants carrying antisense construct of expansin was hampered which means that expansins can be a useful tool in crop improvement programs like breeding for resistance to nematodes.

Although expansins are universal in the plant kingdom they are also found in other organisms like snails where they are thought to have a degradative function in the digestive tracts (Cosgrove and Durachko 1994) and in a small set of phylogenetically diverse bacteria, fungi, and other organisms especially those that colonize plant surfaces (Georgelis et al. 2015). Several microbial expansin proteins have been discovered and reported. These include expansin-like proteins from the Dictyostelium discoideum (Kawata et al. 2015), BsExlxl from Bacillus subtilis (Kerff et al. 2008), HcExlx2 from the marine bacteria Hahella chejuensis (Lee et al. 2010), PcExll from the plant pathogenic bacteria Pectobacterium carotovorum (OlarteLozano et al. 2014) and ScExlxl from the Basidiomycete fungus Schizophylum commune (Tovar-Herrera et al.
2015). These microbial expansins have been shown to possess various capabilities which may be useful in enabling the microbes to attach and colonize plants. This is supported by the presence of such expansins in microbes such as plant pathogenic bacteria, including species of Xanthomonas and Streptomyces and fungal genomes which include plant pathogenic species of Gibberella and Fusarium (Georgelis et al. 2015) that colonize plants. In a broader sense, this presents an opportunity to plant breeders to breed for resistance to such pathogenic attack if the microbes rely solely on the action of their expansin genes. Also, some researchers are evaluating the potential use of these microbial expansins in cellulosic biomass conversion for biofuel production, as a means to disaggregate cellulosic structures (Georgelis et al. 2015).

\section{Future prospects}

Even though not all expansins have the potential for application in crop improvement, several expansins including, but not limited to SIEXPA6, LeExp1, RhEXPA4, TaEXPB23, GmEXPB2, OsEXPA2, OsEXPA17, PnEXPA1, GbEXPATR, MdEXPA12 and NtEXPA4 and 5 have been proved to be useful for improving crops in various areas as highlighted in the text through overexpression and/or RNAi approaches for example. Taking tomatoes as an example, breeding for improved fruit shelf life is still a major objective. Expansins have been proved to play a pivotal role during fruit ripening and softening. Minoia et al. (2015) reported a massive 41 and $46 \%$ fruit firmness enhancement in Slexp1-6 and Slexp1-7 mutant lines, respectively as compared to the control plants. This is in line with earlier reports by Brummell et al. (1999) who showed that suppression of LeExpl (another tomato expansin gene) inhibited polyuronide depolymerization and produced firmer fruits in transgenic tomatoes, while overexpression of the same gene resulted in softer fruits.

As such, new tomato varieties with enhanced fruit firmness could be generated by knock-out or suppression of Slexpl and LeExpl expansin genes using the new genome editing technologies especially Clustered Regularly Interspaced Short Palindromic Repeats (CRISPR) (Carroll 2014). As has been mentioned earlier on, this could be useful in breeding programs in combination with other alleles in the antioxidant or ethylene pathway since CRISPR/Cas can simultaneously introduce multiple gene disruptions (Wang et al. 2013) thus allowing breeders to edit multiple genes in one plant line through a single transformation (Xiong et al. 2015). Bearing in mind that previous manipulation of the polyamine or anthocyanin pathways had deleterious consequences on fruit quality traits such as flavor, texture and aroma despite their contribution in delaying fruit softening (Lovisetto et al. 2015), 
the employment of expansin could be a better option. Depending on the crop and objective, several other ways can be used to manipulate these genes.

\section{Conclusion}

After observing the so many diverse roles played by expansins, it has been concluded that expansins are involved in many morphogenetic processes including germination, fruit ripening, growth of pollen tube, growth of root hairs, defoliation and many others which are yet to be discovered (Kuluev et al. 2013). Although there is still a need to further study and understand these expansins, especially considering that some expansins like RhEXPA4 have been reported to negatively affect plant development when expressed at very high levels, it is also clear that incorporation of expansins in the crop improvement programs presents a potential tool to significantly improve crops in various aspects as highlighted in this paper. Although many crop traits are quantitative and are controlled by multiple genes, expansins, combined with other tools can be useful in manipulating many plant physiological aspects such as germination, stem development, yield and plant's ability to withstand biotic and abiotic stress which has ever since become a concern following the current global warming and climate change issues. As highlighted in this paper, expansins can be used in floriculture industries to manipulate flower sizes through overexpression for example. Use of expansin together with other tools can enhance plants' tolerance to abiotic and biotic stresses and can see a reduction in the use of chemicals or an improvement in the performance of plants under nutrient or salt stress while their use in fruit ripening manipulation can lower postharvest losses which currently hovers above $50 \%$ for fruits and vegetables (Gustavsson et al. 2011). In short, the manipulation of expansins combined with other breeding tools can be a useful strategy to improve our crops. However, the worthy of this information lies in its utilization in crop improvement.

Author contribution statement Prince Marowa, Anming Ding and Yingzhen Kong drafted the manuscript. Prince Marowa collected background information. All authors read and approved the final manuscript.

Acknowledgments This work is supported by The National Key Technology R\&D Program (2015BAD15B03-05), the National Natural Science Foundation of China (31470291) and the Elite Youth Program of CAAS (to Y. K).

\section{Compliance with ethical standards}

Conflict of interest The authors declare that they have no conflict of interest.
Open Access This article is distributed under the terms of the Creative Commons Attribution 4.0 International License (http://crea tivecommons.org/licenses/by/4.0/), which permits unrestricted use, distribution, and reproduction in any medium, provided you give appropriate credit to the original author(s) and the source, provide a link to the Creative Commons license, and indicate if changes were made.

\section{References}

Abuqamar S, Ajeb S, Sham A, Enan MR, Iratni R (2013) A mutation in the expansin-like A2 gene enhances resistance to necrotrophic fungi and hypersensitivity to abiotic stress in Arabidopsis thaliana. Mol Plant Pathol 14(8):813-827

Asif M, Lakhwani D, Pathak S, Gupta P, Bag SK, Nath P, Trivedi P (2014) Transcriptome analysis of ripe and unripe fruit tissue of banana identifies major metabolic networks involved in fruit ripening process. BMC Plant Biol 14(1):316

Azeez A, Sane AP, Tripathi SK, Bhatnagar D, Nath P (2010) The gladiolus GgEXPA1 is a GA-responsive alpha-expansin gene expressed ubiquitously during expansion of all floral tissues and leaves but repressed during organ senescence. Postharvest Biol Technol 58(1):48-56

Bae JM, Kwak MS, Noh SA, Oh MJ, Kim YS, Shin JS (2014) Overexpression of sweetpotato expansin cDNA (IbEXP1) increases seed yield in Arabidopsis. Transgenic Res 23(4):657667

Bashline L, Lei L, Li S, Gu Y (2014) Cell wall, cytoskeleton, and cell expansion in higher plants. Mol Plant 7(4):586-600

Bauerfeind MA, Winkelmann T, Franken P, Druege U (2015) Transcriptome, carbohydrate, and phytohormone analysis of Petunia hybrida reveals a complex disturbance of plant functional integrity under mild chilling stress. Front Plant Sci 6:583

Belfield EJ, Ruperti B, Roberts JA, Mcqueen-mason S (2005) Changes in expansin activity and gene expression during ethylene-promoted leaflet abscission in Sambucus nigra. J Exp Bot 56(413):817-823

Boron AK, Van Loock B, Suslov D, Markakis MN, Verbelen JP, Vissenberg K (2015) Over-expression of AtEXLA2 alters etiolated arabidopsis hypocotyl growth. Ann Bot 115(1):67-80

Brummell D, Harpster M, Civello P, Palys J, Bennett A, Dunsmuir P (1999) Modification of expansin protein abundance in tomato fruit alters softening and cell wall polymer metabolism during ripening. Plant Cell 11(11):2203-2216

Carroll D (2014) Genome engineering with targetable nucleases. Annu Rev Biochem 83:409-439

Carvajal F, Palma F, Jamilena M, Garrido D (2015) Cell wall metabolism and chilling injury during postharvest cold storage in zucchini fruit. Postharvest Biol Technol 108(September):68-77

Catling H, Puckridge D, Hille RLD (1988) The environment of Asian deepwater rice. In: 1987 International Deepwater Rice Workshop Manila. International Rice Research Institute

Chaves MM, Maroco JP, Pereira JS (2003) Understanding plant responses to drought-from genes to the whole plant. Funct Plant Biol 30(3):239-264

Chen F, Dahal P, Bradford KJ (2001) Two tomato expansin genes show divergent expression and localization in embryos during seed development and germination. Plant Physiol 127(3):928-936

Cho HT, Cosgrove DJ (2000) Altered expression of expansin modulates leaf growth and pedicel abscission in Arabidopsis thaliana. Proc Natl Acad Sci USA 97(17):9783-9788

Cho HT, Cosgrove DJ (2002) Regulation of root hair initiation and expansin gene expression in Arabidopsis. Plant Cell 14(12):3237-3253 
Cho HT, Kende H (1997a) Expansins and lnternodal crowth of deepwater rice. Plant Physiol 2(113):1145-1151

Cho HT, Kende H (1997b) Expression of expansin genes is correlated with growth in deepwater rice. Plant Cell 9(9):1661-1671

Choi D, Lee Y, Cho HT, Kende H (2003) Regulation of expansin gene expression affects growth and development in transgenic rice plants. Plant Cell Online 15(6):1386

Choi D, Kim JH, Lee Y (2008) Expansins in plant development. Adv Bot Res 47(08):47-97

Civello PM, Powell AL, Sabehat A, Bennett AB (1999) An expansin gene expressed in ripening strawberry fruit. Plant Physiol 121(4):1273-1280

Cosgrove DJ (2000) New genes and new biological roles for expansins. Curr Opin Plant Biol 3(1):73-78

Cosgrove DJ (2015) Plant expansins: diversity and interactions with plant cell walls. Curr Opin Plant Biol 25:162-172

Cosgrove DJ, Durachko DM (1994) Autolysis and extension of isolated walls from growing cucumber hypocotyls. J Exp Bot 45(Special Issue):1711-1719

Cosgrove DJ, Li LC, Cho H, Hoffmann-benning S, Richard C, Blecker D (2002) The growing world of expansins. Plant Cell Physiol 43(12):1436-1444

Dai S, Wang T, Yan X, Chen S (2007) Proteomics of pollen development and germination. J Proteome Res 6(12):4556-4563

Dai F, Zhang C, Jiang X, Kang M, Yin X, Lu P, Gao J (2012) RhNAC2 and RhEXPA4 are involved in regulation of dehydration tolerance during the expansion of rose petals. Plant Physiol 160:2064-2082

Dal Santo S, Vannozzi A, Tornielli GB, Fasoli M, Venturini L, Pezzotti M, Zenoni S (2013) Genome-wide analysis of the expansin gene superfamily reveals grapevine-specific structural and functional characteristics. PLoS One 8(4):e62206

Devi MJ, Taliercio EW, Sinclair TR (2015) Leaf expansion of soybean subjected to high and low atmospheric vapour pressure deficits. J Exp Bot 66(7):1845-1850

Ding X, Cao Y, Huang L, Zhao J, Xu C, Li X, Wang S (2008) Activation of the indole-3-acetic acid-amido synthetase GH3-8 suppresses expansin expression and promotes salicylate- and jasmonate-independent basal immunity in rice. Plant Cell Online 20(1):228-240

Downes BP, Crowell DN (1998) Cytokinin regulates the expression of a soybean beta-expansin gene by a post-transcriptional mechanism. Plant Mol Biol 37(3):437-444

Farhad M (2014) Screening wheat genotypes for coleoptile length: a trait for drought tolerance. Am J Agric For 2(6):237

Finch-Savage WE, Leubner-Metzger G (2006) Seed dormancy and the control of germination. New Phytol 171(3):501-523

Fudali S, Janakowski S, Sobczak M, Griesser M (2008a) Two tomato alpha-expansins show distinct spatial and temporal expression patterns during development of nematode-induced syncytia. Physiol Plant 132:370-383

Fudali S, Sobczak M, Janakowski S, Griesser M, Grundler FM, Golinowski W (2008b) Expansins are among plant cell wall modifying agents specifically expressed during development of nematode-induced syncytia. Plant Signal Behav 3(11):969-971

Fukuda H (ed) (2014) Plant cell wall patterning and cell shape. Wiley, Hoboken

Gaete-Eastman C, Morales-Quintana L, Herrera R, Moya-León MA (2015) In-silico analysis of the structure and binding site features of an $\alpha$-expansin protein from mountain papaya fruit (VpEXPA2), through molecular modeling, docking, and dynamics simulation studies. J Mol Model 21(5):115

Geilfus CM, Ober D, Eichacker LA, Mühling KH, Zörb C (2015) Down-regulation of ZmEXPB6 (Zea mays $\beta$-expansin 6) protein is correlated with salt-mediated growth reduction in the leaves of Z. mays L. J Biol Chem 290(18):11235-11245
Georgelis N, Nikolaidis N, Cosgrove DJ (2015) Bacterial expansins and related proteins from the world of microbes. Appl Microbiol Biotechnol 99(9):3807-3823

Gookin TE, Hunter D, Reid MS (2003) Temporal analysis of alpha and beta-expansin expression during floral opening and senescence. Plant Sci 164(5):769-781

Green PB (1999) Expression of pattern in plants: combining molecular and calculus-based biophysical paradigms. Am J Bot 86(8):1059-1076

Guo W, Zhao J, Li X, Qin L, Yan X, Liao H (2011) A soybean $\beta$ expansin gene GmEXPB2 intrinsically involved in root system architecture responses to abiotic stresses. Plant J 66(3):541-552

Gustavsson J, Cederberg C, Sonesson U, van Otterdijk R, Meybeck A (2011) Global food losses and food waste: extent causes and prevention. Food and Agriculture Organization (FAO) of the United Nations, Rome

Han Y, Chen Y, Yin S, Zhang M, Wang W (2015) Over-expression of TaEXPB23, a wheat expansin gene, improves oxidative stress tolerance in transgenic tobacco plants. J Plant Physiol 173:62-71

Harmer SE, Orford SJ, Timmis JN (2002) Characterisation of six alpha-expansin genes in Gossypium hirsutum (upland cotton). Mol Genet Genom 268(1):1-9

Harrison EP, Mcqueen-mason SJ, Manning K (2001) Expression of six expansin genes in relation to extension activity in developing strawberry fruit. J Exp Bot 52(360):1437-1446

Hayama H, Shimada T, Haji T, Ito A, Kashimura Y, Yoshioka H (2000) Molecular cloning of a ripening-related expansin cDNA in peach: evidence for no relationship between expansin accumulation and change in fruit firmness during storage. J Plant Physiol 573(1185):567-573

Hoekstra FA, Golovina EA, Buitink J (2001) Mechanisms of plant desiccation tolerance. Trends Plant Sci 6(9):431-438

Holdsworth MJ, Soppe WJJ (2008) Molecular networks regulating Arabidopsis seed maturation, after-ripening, dormancy and germination. New Phytol 179:33-54

Huang J, Takano T, Akita S (2000) Expression of $\alpha$-expansin genes in young seedlings of rice (Oryza sativa L.). Planta 211(4):467-473

Ithal N, Recknor J, Nettleton D, Hearne L, Maier T, Baum TJ, Mitchum MG (2007) Parallel genome-wide expression profiling of host and pathogen during soybean cyst nematode infection of soybean. Mol Plant Microbe Interact 20(3):293-305

Jones L, McQueen-Mason S (2004) A role for expansins in dehydration and rehydration of the resurrection plant Craterostigma plantagineum. FEBS Lett 559(1-3):61-65

Kapu NUS, Cosgrove DJ (2010) Changes in growth and cell wall extensibility of maize silks following pollination. J Exp Bot 61(14):4097-4107

Kawata T, Nakamura Y, Saga Y, Iwade Y, Ishikawa M, Sakurai A, Shimada N (2015) Implications of expansin-like 3 gene in Dictyostelium morphogenesis. Springerplus 4(1):190

Kende H, Bradford KJ, Brummell Da, Cho HT, Cosgrove DJ, Fleming AJ, Voesenek LACJ (2004) Nomenclature for members of the expansin superfamily of genes and proteins. Plant Mol Biol 55(3):311-314

Kerff F, Amoroso A, Herman R, Sauvage E, Petrella S, Filée P (2008) Crystal structure and activity of Bacillus subtilis YoaJ (EXLX1), a bacterial expansin that promotes root colonization. PNAS 105:16876-16881

Klink VP, Overall CC, Alkharouf NW, Macdonald MH, Matthews BF (2007) Laser capture microdissection (LCM) and comparative microarray expression analysis of syncytial cells isolated from incompatible and compatible soybean (Glycine max) roots infected by the soybean cyst nematode (Heterodera glycines). Planta 226(6):1389-1409

Kuluev BR, Knyazev AB, Lebedev YP, Chemeris AV (2012) Morphological and physiological characteristics of transgenic 
tobacco plants expressing expansin genes: AtEXP10 from Arabidopsis and PnEXPA1 from poplar. Russ J Plant Physiol 59(1):97-104

Kuluev BR, Safiullina MG, Knyazev AV, Chemeris AV (2013) Effect of ectopic expression of NtEXPA5 gene on cell size and growth of organs of transgenic tobacco plants. Russ J Dev Biol 44(1):28-34

Kwasniewski M, Szarejko I (2006) Molecular cloning and characterization of beta-expansin gene related to root hair formation in barley. Plant Physiol 141(3):1149-1158

Kwon YR, Lee HJ, Kim KH, Hong SW, Lee SJ, Lee H (2008) Ectopic expression of Expansin3 or Expansin $\beta 1$ causes enhanced hormone and salt stress sensitivity in Arabidopsis. Biotechnol Lett 30(7):1281-1288

Lausser A, Kliwer I, Srilunchang KO, Dresselhaus T (2010) Sporophytic control of pollen tube growth and guidance in maize. J Exp Bot 61(3):673-682

Lee Y, Kende H (2001) Expression of beta-expansins is correlated with internodal elongation in deepwater rice. Plant Physiol 127(2):645-654

Lee Y, Kende H (2002) Expression of alpha-expansin and expansinlike genes in deepwater rice. Plant Physiol 130(3):1396-1405

Lee HW, Kim J (2013) EXPANSINA17 Up-Regulated by LBD18/ ASL20 promotes lateral root formation during the auxin response. Plant Cell Physiol 54(10):1600-1611

Lee Y, Choi D, Kende H (2001) Expansins: ever-expanding numbers and functions. Curr Opin Plant Biol 4(6):527-532

Lee DK, Ahn JH, Song S-K, Choi Y Do, Lee JS (2003) Expression of an expansin gene is correlated with root elongation in soybean. Plant Physiol 131(3):985-997

Lee HJ, Lee S, Ko HJ, Kim KH, Choi I G (2010) An expansin-like protein from Hahella chejuensis binds cellulose and enhances cellulase activity. Mol Cells 29(4):379-385

Li L, Bedinger PA, Volk C, Jones AD, Cosgrove DJ (2003a) Purification and characterization of four beta-expansins (Zea $\mathrm{m} 1$ isoforms) from maize pollen. Plant Physiol 132(4):2073-2085

Li Y, Jones L, McQueen-Mason S (2003b) Expansins and cell growth. Curr Opin Plant Biol 6(6):603-610

Li F, Xing S, Guo Q, Zhao M, Zhang J, Gao Q, Wang W (2011) Drought tolerance through over-expression of the expansin gene TaEXPB23 in transgenic tobacco. J Plant Physiol 168(9):960 966

Li F, Han Y, Feng Y, Xing S, Zhao M, Chen Y, Wang W (2013) Expression of wheat expansin driven by the RD29 promoter in tobacco confers water-stress tolerance without impacting growth and development. J Biotechnol 163(3):281-291

Li X, Zhao J, Walk TC, Liao H (2014) Characterization of soybean $\beta$ expansin genes and their expression responses to symbiosis, nutrient deficiency and hormone treatment. Appl Microbiol Biotechnol 98(6):2805-2817

Li AX, Han YY, Wang X, Chen YH, Zhao MR, Zhou S-M, Wang W (2015a) Root-specific expression of wheat expansin gene TaEXPB23 enhances root growth and water stress tolerance in tobacco. Environ Exp Bot 110:73-84

Li W, Wang F, Wang J, Fan F, Zhu J, Yang J, Zhong W (2015b) Overexpressing CYP71Z2 enhances resistance to bacterial blight by suppressing auxin biosynthesis in rice. Plos One 10(3)

Li Y, Tu L, Pettolino FA, Ji S, Hao J, Yuan D, Zhang X (2015c) GbEXPATR, a species-specific expansin, enhances cotton fibre elongation through cell wall restructuring. Plant Biotechnol $\mathrm{J}: 1-13$

Lovisetto A, Masiero S, Rahim MA, Mendes MAM, Casadoro G (2015) Fleshy seeds form in the basal Angiosperm Magnolia grandiflora and several MADS-box genes are expressed as fleshy seed tissues develop. Evol Dev 17(1):82-91
Lü P, Kang M, Jiang X, Dai F, Gao J, Zhang C (2013) RhEXPA4, a rose expansin gene, modulates leaf growth and confers drought and salt tolerance to Arabidopsis. Planta 237(6):1547-1559

Ma J, Li Z, Wang B, Sui S, Li M (2012) Cloning of an expansin gene from chimonanthus praecox flowers and its expression in flowers treated with ethephon or 1-methylcyclopropene. Hortscience 47(10):1472-1477

Ma N, Wang Y, Qiu S, Kang Z, Che S, Wang G, Huang J (2013) Overexpression of OsEXPA8, a root-specific gene, improves rice growth and root system architecture by facilitating cell extension. PLoS One 8(10)

McQueen-Mason S, Durachko DM, Cosgrove DJ (1992) Two endogenous proteins that induce cell wall extension in plants. Plant Cell 4:1425-1433

Minoia S, Boualem A, Marcel F, Troadec C, Quemener B, Cellini F, Bendahmane A (2015) Induced mutations in tomato SlExp1 alter cell wall metabolism and delay fruit softening. Plant Sci:1-8

Mollet JC, Leroux C, Dardelle F, Lehner A (2013) Cell wall composition, biosynthesis and remodeling during pollen tube growth. Plants 2(1):107-147

Morris K, Linkies A, Müller K, Oracz K, Wang X, Lynn JR, FinchSavage WE (2011) Regulation of seed germination in the close Arabidopsis relative Lepidium sativum: a global tissue-specific transcript analysis. Plant Physiol 155(4):1851-1870

Noh A, Lee H, Kim Y, Paek K, Beatrice M (2013) Down-regulation of the IbEXP1 gene enhanced storage root. In: Posidonia oceanica cadmium induces changes in DNA development in sweetpotato methylation and chromatin patterning, 64(1):129142

O’Malley RC, Lynn DG (2000) Expansin message regulation in parasitic angiosperms: marking time in development. Plant Cell 12(8):1455-1465

Olarte-Lozano M, Mendoza-Nuñez MA, Pastor N, Segovia L, FolchMallol J, Martínez-Anaya C (2014) PcExl1 a novel acid expansin-like protein from the plant pathogen Pectobacterium carotovorum, binds cell walls differently to BsEXLX1. PLoS One 9(4):e95638

Palapol Y, Kunyamee S, Thongkhum M, Ketsa S, Ferguson IB, Van Doorn WG (2015) Expression of expansin genes in the pulp and the dehiscence zone of ripening durian (Durio zibethinus) fruit. J Plant Physiol 182:33-39

Park CH, Kim TW, Son SH, Hwang JY, Lee SC, Chang SC, Kim SK (2010) Brassinosteroids control AtEXPA5 gene expression in Arabidopsis thaliana. Phytochemistry 71(4):380-387

Pien S, Wyrzykowska J, McQueen-Mason S, Smart C, Fleming A (2001) Local expression of expansin induces the entire process of leaf development and modifies leaf shape. Proc Natl Acad Sci USA 98(20):11812-11817

Rayle DL, Cleland RE (1992) The acid growth theory of auxininduced cell elongation is alive and well. Plant Physiol 99(4):1271-1274

Rose JKC, Bennett AB (1999) Cooperative disassembly of the cellulose-xyloglucan network of plant cell walls: parallels between cell expansion and fruit ripening. Trends Plant Sci 4(5):176-183

Rose JK, Lee HH, Bennett AB (1997) Expression of a divergent expansin gene is fruit-specific and ripening-regulated. Proc Natl Acad Sci USA 94(11):5955-5960

Rose JKC, Cosgrove DJ, Albersheim P, Darvill AG, Bennett AB (2000) Detection of expansin proteins and activity during tomato fruit ontogeny. Plant Physiol 123(4):1583-1592

Sampedro J, Cosgrove DJ (2005) The expansin superfamily. Genome Biol 6:242

Shimizu Y, Aotsuka S, Hasegawa O, Kawada T, Sakuno T, Sakai F, Hayashi T (1997) Changes in levels of mRNAs for cell wall- 
related enzymes in growing cotton fiber cells. Plant Cell Physiol 38(3):375-378

Tovar-Herrera OE, Batista-García RA, Sánchez-Carbente MDR, Iracheta-Cárdenas MM, Arévalo-Niño K, Folch-Mallol JL (2015) A novel expansin protein from the white-rot fungus Schizophyllum commune. PLoS One 10(3):e0122296

Trivedi PK, Nath P (2004) MaExp1, an ethylene-induced expansin from ripening banana fruit. Plant Sci 167(6):1351-1358

Valdivia ER, Cosgrove DJ, Stephenson AG (2006) Role of accelerated style senescence in pathogen defense. Am $\mathrm{J}$ Bot 93(11):1725-1729

Valdivia ER, Wu Y, Li L, Cosgrove DJ, Stephenson AG (2007) A group-1 grass pollen allergen influences the outcome of pollen competition in maize. PLoS One 2(1):e154

Valdivia ER, Stephenson AG, Durachko DM, Cosgrove D (2009) Class B beta-expansins are needed for pollen separation and stigma penetration. Sex Plant Reprod 22:141-152. doi:10.1007/ s00497-009-0099-y

Voegele A, Linkies A, Müller K, Leubner-Metzger G (2011) Members of the gibberellin receptor gene family GID1 (GIBBERELLIN INSENSITIVE DWARF1) play distinct roles during Lepidium sativum and Arabidopsis thaliana seed germination. J Exp Bot 62(14):5131-5147

Vreeburg RAM, Benschop JJ, Peeters AJM, Colmer TD, Ammerlaan AHM, Staal M, Elzenga TM, Staals RH, Darley CP, McQueenMason SJ, Voesenek LACJ (2005) Ethylene regulates fast apoplastic acidification and expansin A transcription during submergence-induced petiole elongation in Rumex palustris. Plant J 43(4):597-610

Wang H, Yang H, Shivalila CS, Dawlaty MM, Cheng AW, Zhang F, Jaenisch R (2013) One-step generation of mice carrying mutations in multiple genes by CRISPR/cas-mediated genome engineering. Cell 153(4):910-918

Wei P, Chen S, Zhang X, Zhao P, Xiong Y, Wang W, Wang X (2011a) An a-expansin, VfEXPA1, is involved in regulation of stomatal movement in Vicia faba L. Chin Sci Bull 56(33):3531-3537

Wei P-C, Zhang X-Q, Zhao P, Wang X-C (2011b) Regulation of stomatal opening by the guard cell expansin AtEXPA1. Plant Signal Behav 6(5):740-742

Weitbrecht K, Müller K, Leubner-Metzger G (2011) First off the mark: early seed germination. J Exp Bot 62(10):3289-3309
Won S, Choi S, Kumari S, Cho M, Lee SH, Cho H (2010) Root hairspecific EXPANSIN B genes have been selected for Graminaceae root hairs. Mol Cells 30(4):369-376

Xing SC, Li F, Guo QF, Liu DR, Zhao XX, Wang W (2009) The involvement of an expansin geneTaEXPB23 from wheat in regulating plant cell growth. Biol Plant 53(3):429-434

Xiong J-S, Ding J, Li Y (2015) Genome-editing technologies and their potential application in horticultural crop breeding. Hortic Res 2(April): 15019

Xu Q, Xu X, Shi Y, Xu J, Huang B (2014) Transgenic tobacco plants overexpressing a grass PpEXP1 gene exhibit enhanced tolerance to heat stress. PLoS One 9(7):e100792

Yan A, Wu M, Yan L, Hu R, Ali I, Gan Y (2014) AtEXP2 is involved in seed germination and abiotic stress response in Arabidopsis. PLoS One 9(1):1-10

Yu Z, Kang B, He X, Lv S, Bai Y, Ding W, Wu P (2011) Root hairspecific expansins modulate root hair elongation in rice. Plant $\mathrm{J}$ 66(5):725-734

Zhang W, Yan H, Chen W, Liu J, Jiang C, Jiang H, Cheng B (2014) Genome-wide identification and characterization of maize expansin genes expressed in endosperm. Mol Genet Genomics 289(6):1061-1074

Zhao MR, Li F, Fang Y, Gao Q, Wang W (2011) Expansin-regulated cell elongation is involved in the drought tolerance in wheat. Protoplasma 248(2):313-323

Zhao MR, Han YY, Feng YN, Li F, Wang W (2012) Expansins are involved in cell growth mediated by abscisic acid and indole-3acetic acid under drought stress in wheat. Plant Cell Rep 31:671-685

Zhou J, Xie J, Liao H, Wang X (2014) Overexpression of $\beta$-expansin gene GmEXPB2 improves phosphorus efficiency in soybean. Physiol Plant 150(2):194-204

Zhou S, Han Y, Chen Y, Kong X, Wang W (2015) The involvement of expansins in response to water stress during leaf development in wheat. J Plant Physiol 183:64-74

Zörb C, Mühling KH, Kutschera U, Geilfus C-M (2015) Salinity stiffens the epidermal cell walls of salt-stressed maize leaves: is the epidermis growth-restricting? PLoS One 10(3):e0118406

Zou H, Wenwen Y, Zang G, Kang Z, Zhang Z, Huang J, Wang G (2015). OsEXPB2, a $\beta$-expansin gene, is involved in rice root system architecture. Mol Breed 35(1) 